\title{
Electrochemistry in the twenty-first century-future trends and perspectives
}

\author{
Rubin Gulaboski ${ }^{1}$
}

Received: 3 February 2020 / Revised: 3 February 2020 / Accepted: 11 March 2020 / Published online: 16 March 2020

(C) Springer-Verlag GmbH Germany, part of Springer Nature 2020

Since the 1959 Heyrovsky's Nobel Prize for polarography, it has been 60 years on for the Nobel Prize for Chemistry 2019 to be awarded to a team of scientists working on "pure" electrochemistry. The development of lithium-ion batteries [1] is probably the most recognizable applicative achievement of electrochemistry in the field of energy storage. Although it has huge applications in many different fields, we must admit that electrochemical techniques have been considered for a long time as a "secondary research tool." The award of Chemistry Nobel Prize for 2019 will be, without doubts, a turning point for many electrochemists to further pursue their research even more intensively. Indeed, one expects that electrochemistry will still offer new possibilities for further development in the field of rechargeable batteries and energy storage. However, we witness in the last 50 years that electrochemistry is a highly interdisciplinary branch, finding applications in many fields of chemical industry, metallurgy, pharmacy, medicine, biochemistry, synthesis of new materials, and nano-chemistry. The major aspect of electrochemistry that distinguishes it from other branches of physical chemistry is the ubiquity of its applications. It studies not only the processes of charge (electron and ion) transfer but also important phenomena such as adsorption, phase transformation, chemical reactivity, catalysis, energy conversion, and many more. The molecular systems that are analyzed with electrochemical techniques are very versatile, ranging from small ions and molecules [2] to large biomolecules (enzymes) [3]. As electrochemistry is closely related to electronics and informatics, we expect to witness fast commercial development of selective and reliable multi-analyzing biosensors. Designed for simultaneous detection of relevant physiological substances and incorporated in the human body in a form of small electronic sensors, these devices will contribute for "intime" recognition of many health-related physiological

Rubin Gulaboski

rubin.gulaboski@ugd.edu.mk

1 Faculty of Medical Sciences, Goce Delcev University, Stip, Macedonia conditions. Indeed, the development of selective "microbiological" electrochemical sensors that will be able to recognize quickly specific viruses and bacteria is a highly challenging task that might involve the electrochemical techniques in the field of fast and accurate diagnosis of many infectious diseases. The application of electrochemical techniques in tasks related to green chemistry, fuel cell development, nano-chemistry, and for analyzing the chemical features of new materials and substances will further go on with high intensity. The search for novel electrode materials and electrolytes with specific features will, indeed, bring electrochemical science to a higher level. Although electrochemistry has made a huge impact in many fields, we have to admit that it is not a very attractive science out of the inner circle of people working on it. In my opinion, to get a better future of electrochemical science, the biggest challenge will be to hire excellent young students interested in doing science, which will bring fresh ideas. Unfortunately, the conditions in many societies in the last 20 years contribute to keep most of young people away from doing science. Promoting the achievements and significance of electrochemistry should start from the basic school. It is up to the electrochemists to develop relevant strategies for bigger promotion of electrochemistry among the youngsters. Only with outstanding young people and fresh ideas, we might expect to see rapid development of electrochemistry in new directions for the years to come.

\section{References}

1. Mizushima K, Jones PC, Wiseman PJ, Goodenough JB (1980) LixCoO2 $(0<\mathrm{x}<-1)$ : a new cathode material for batteries of high energy density. Mater Res Bull 15:783-789

2. Bard AJ, Faulkner LR (2001) Electrochemical methods, 2nd edn. John Wiley \& Sons, Inc., Hoboken

3. Léger C, Bertrand P (2007) Direct electrochemistry of redox enzymes as a tool for mechanistic studies. Chem Rev 108:2379-2438

Publisher's note Springer Nature remains neutral with regard to jurisdictional claims in published maps and institutional affiliations. 